\title{
Field-Based Evidence of Single and Few Doses of Annual Ivermectin Treatment Efficacy in Eliminating Skin Microfilaria Load after a Decade of Intervention
}

\author{
Hudu O. Osue*
}

\footnotetext{
OPEN ACCESS

Citation: Hudu O. Osue. Field-Based Evidence of Single and Few Doses of Annual Ivermectin Treatment Efficacy in Eliminating Skin Microfilaria Load after a Decade of Intervention. Ethiop J Health Sci 2017;27(1):129. doi: http://dx.doi.org/10.4314/ejhs.v27i2.5 Received: December 7, 2016 Accepted: December 8, 2016 Published: March 1, 2017

Copyright: () 2015 Hudu.O. This is an open access article distributed under the terms of the Creative Commons Attribution License, which permits unrestricted use, distribution, and reproduction in any medium, provided the original author and source are credited. Funding: Nigerian Institute for Trypanosomiasis (and Onchocerciasis)

Research, Kaduna, Nigeria.

Competing Interests: The authors declare that this manuscript was approved by all authors in its form and that no competing interest exists.

Affiliation and Correspondence:

${ }^{1}$ Nigerian Institute for

Trypanosomiasis (and Onchocerciasis)

Research (NITR), Kaduna, Nigeria

*Email: osueho@yahoo.com
}

\begin{abstract}
BACKGROUND: Impact assessment of community-based ivermectin treatment control of onchocerciasis is required to determine its effectiveness. This study was conducted to evaluate geographic coverage and demographic ivermectin treatment compliance.
\end{abstract}

METHODS: The number of village dosage were obtained from the community based distributors. Bioclinical data of participants comprising gender, age, number of treatment received from inception and dosage were obtained. Each participant was subjected to physical examination for palpable nodule and other skin clinical signs and symptoms of onchocerciasis. Visual acuity test was done using the Snellen illiterate E-chart. Eye examination was performed using touch loop and handheld ophthalmoscope. Skin snips from both iliac crests were incubated overnight at 28$32^{\circ} \mathrm{C}$ and emerged micrifilaria enumerated under an inverted microscope. The changes in epidemiological indices at post-decade of mass drug administration were compared with baseline data.

RESULTS: Village annual ivermectin treatment doses averaged 62\%, ranging between 10-100\%. Individual treatment compliance rate was generally low with an average of 4 treatments and a range between 0-10. Despite variations in treatment compliance, there were significant improvements in some onchocercal morbidities. These include reduced number and severity of itching, visual impairment, papular onchodermatitis, onchocercomata (palpable nodules) and leopard skin. Ivermectin treatment halted development of new blind cases, except the case of a man who had optic nerve disease and became blind 2 years after ivermectin treatment had commenced. There was a significant overall reduction in parasite burden with very low mean skin microfilaria load of $1.7 m f$ per skin snip and 3.7\% skin mf prevalence, compared to baseline data of $17.7 \mathrm{mf}$ and $37.9 \%$ respectively. The palpable nodule was also drastically reduced from $14.5 \%$ to $6.4 \%$. Outcome of this study has practically demonstrated that even a single dose ivermectin treatment is capable of clearing skin mf load on a longterm basis. This assertion is exemplified by the result obtained from Bomjock village that had taken treatment only at inception, and the prevalence rate was reduced from $70 \%$ to about $9.0 \%$ at postdecade of intervention.

DOI: http://dx.doi.org/10.4314/ejhs.v27i2.5 
CONCLUSION: It can be inferred that high demographic coverage with annual treatment doses, it is feasible to attain a shorter time (within a decade) contrary to the anticipated longer-term projection.

KEYWORDS: Ivermectin, Microfilaria, Treatment Compliance, Onchocerciasis, Onchodermatitis, Visual Impairment

\section{INTRODUCTION}

Concerted efforts to control onchocerciasis had relied on strategies directed at reducing or eliminating the vector using insecticides (larvicides). Its setback includes the vast landmass, negative environmental effects and huge costs to sustain the project (1). Secondly, two drugs, diethyl carbamazine (DEC) and suramin available for treatment were very toxic. Thirdly, nodulectomy campaign embarked upon to eliminate adult worms could not achieve the desired results because not all nodules can be detected by palpation as cryptic infections made this control approach not feasible. A foreseeable effective and affordable control strategy emerged when ivermectin previously patented for veterinary use was proven to have microfilaricidal activity (2). More importantly, the drug was not found associated with serious side effects and therefore suited its use as mass drug administration (MDA) through mass distribution to endemic rural and often remote human settlements. Prior to implementing MDA with Mectizan or ivermectin or Stromector, over 40 million Nigerians were exposed to Onchocerciasis; 20 million were infected and about 120,000 went blind from the disease (3). Coincidentally, most of the people infected or at risk of infection were poor peasant farmers who cannot afford the drug and have no access to health facility. Therefore, the development of a novel control strategy called community directed treatment with ivermectin (ComDTI) was highly welcome. With the biannual treatment strategy adopted in six Latin American onchocerciasis endemic countries have proved adequate in eliminating the disease $(4,5)$ within a record time frame.
Annual distribution of Mectizan started in Nigeria in 1992 under the National Primary Health Care. The study area comprised six farming villages located within onchocerciasis mesoendemic focus as described (6). The villages were enlisted into the National Mectizan Distribution Program in 1994. Before the commencement of ivermectin distribution in the study villages, baseline data on prevalence and intensity of onchocercal related clinical manifestations, parasitological (skin microfilarial load and presence of palpable nodule) were obtained (7). Various epidemiological mathematical models have been designed to project the duration for treatment that may likely achieve the eradication of onchocerciasis. Among them are the projection by ONCHOSIM (onchocerciasis simulation model), a microsimulation mathematical model of the dynamics of onchocerciasis transmission, to explore the potentials of a hypothetical macrofilaricidal drug for the elimination of onchocerciasis under different epidemiological conditions (8). In all cases, a 10-year programme of annual macrofilariciding was considered. A modelling stimulation SIMON also predicted that between 10-15 years will be needed to attain eradication of $\mathrm{mf}$ (9). Just as it was earlier envisaged, treatment was required to last beyond the adult life span estimated to be between 9-15 years. According to Plaiser et al. and Turner et al. $(10,11)$, the ONCHOSIM and the epidemiology of onchocerciasis (EPIONCHO) both projected that in mesoendemic areas, the provisional operational threshold for treatment interruption followed by surveillance (pOTTIS) can be reached with annual treatment. The strategy may be insufficient in very highly hyperendemic areas, or would require prolonged continuation of treatment (12). Thus, the principal challenge for onchocerciasis control is to deliver ivermectin treatment to all target communities and to sustain high treatment coverage over a very long period (13). Therefore, the need to evaluate the long-term impact of ComDTI on public health and the transmission potential based on host parasite reservoir is imperative (14). Monitoring is a key issue to ascertain the level of treatment compliance that would impact on this control strategy. More importantly, the observed continued transmission

DOI: http://dx.doi.org/10.4314/ejhs.v27i2.5 
after a decade of ivermectin treatment intervention in Cameroon (15) and the clear evidence of onchocerciasis elimination in parts of Senegal and Mali, and in Nigeria as variously reported $(16,17,18)$ showed that annual ivermectin treatment can effectively be used in the eradication of onchocerciasis. Impact of different levels of compliance to treatment at post decade of MDA on skin mf load, nodule rate and clinical (eye and skin) manifestations is presented in this report.

\section{MATERIALS AND METHODS}

Study area and sample population: The study area included ten villages within Gurara river basin of Kachia Local Government Area (LGA) of Kaduna State, Nigeria. Six sentinel villages had baseline data while four control villages were without baseline data. The area is within latitude $9^{\circ} 37^{\prime}$ to $9^{\circ} 45^{\prime} \mathrm{N}$ and longitude $7^{\circ} 40^{\prime}$ to $8^{\circ} \mathrm{E}$. The sample population $(n=438)$ from the sentinel communities was comprised of males $(n=220)$ and females $(n=218)$ drawn from among the prebaseline sample population. Only those who voluntarily consented to participate were examined for skin diseases (including palpation for nodule and skin snipping), and were subjected to visual acuity test for each eye. Subjects were between the ages of 14-90 years. The control study population $(n=194)$ was made up of males $(n=90)$ and females $(n=104)$ between the ages of 15-90 years. Unlike the others, Ibika community was farther away from the study area and was excluded from the MDA at inception based on the outcome of the rapid epidemiological mapping of onchocerciasis (REMO) that was conducted.

Experimental design: Emerged microfilariae from skin snips taken from both iliac crests were incubated at ambient temperature between 28$32^{\circ} \mathrm{C}$ over night and enumerated under inverted microscope using tally counter. Each patient was examined for skin clinical manifestations according to Murdoch et al. (19), and visual acuity
(VA) for each eye was assessed using illiterate Echart and counting of fingers at 6 and 3 meter distance. Eye examination was performed using touch loop and handheld ophthalmoscope. The number of treatment taken and reasons for not taking the treatment were obtained from individuals. Information on the number of annual treatment administered to the village was obtained from the community based distributors and compared to information provided by the village heads.

Ethics: This project was approved by the Research and Development Committee of the Nigerian Institute for Trypanosomiasis (and Onchocerciasis) Research. All procedures in the collection of human samples were obtained in accordance to the Helsinki Declaration of 1975 (as revised in 1983). The villagers were briefed in their local dialect, and only those who volunteered and consented were enlisted to participate in the project.

\section{RESULTS}

The number of persons $(n=438)$ who voluntarily participated and were examined in this long-term follow-up study at 10 years after commencement of ivermectin treatment intervention represented about $80 \%$ of the baseline sample population. Only few participants $(2.5 \%)$ of the sample population immigrated into the study area within the period of 1994 to 2003. The number of emigrants could not be assessed. There was low level of annual Mectizan ${ }^{\circledR}$ distribution to some villages. The rate of non-compliance, which include persons who did not take any ivermectin were $17.5 \%(n=65)$ while $82.5 \%(n=373)$ of the sample population $(n=438)$ had taken one or more doses. There was a decrease from the number of persons who received one dose $17 \%$ followed by those that received 2 and 4 doses with $15.9 \%$ $(n=59)$, and only one person $(0.3 \%)$ received 9 doses (Figure 1). 


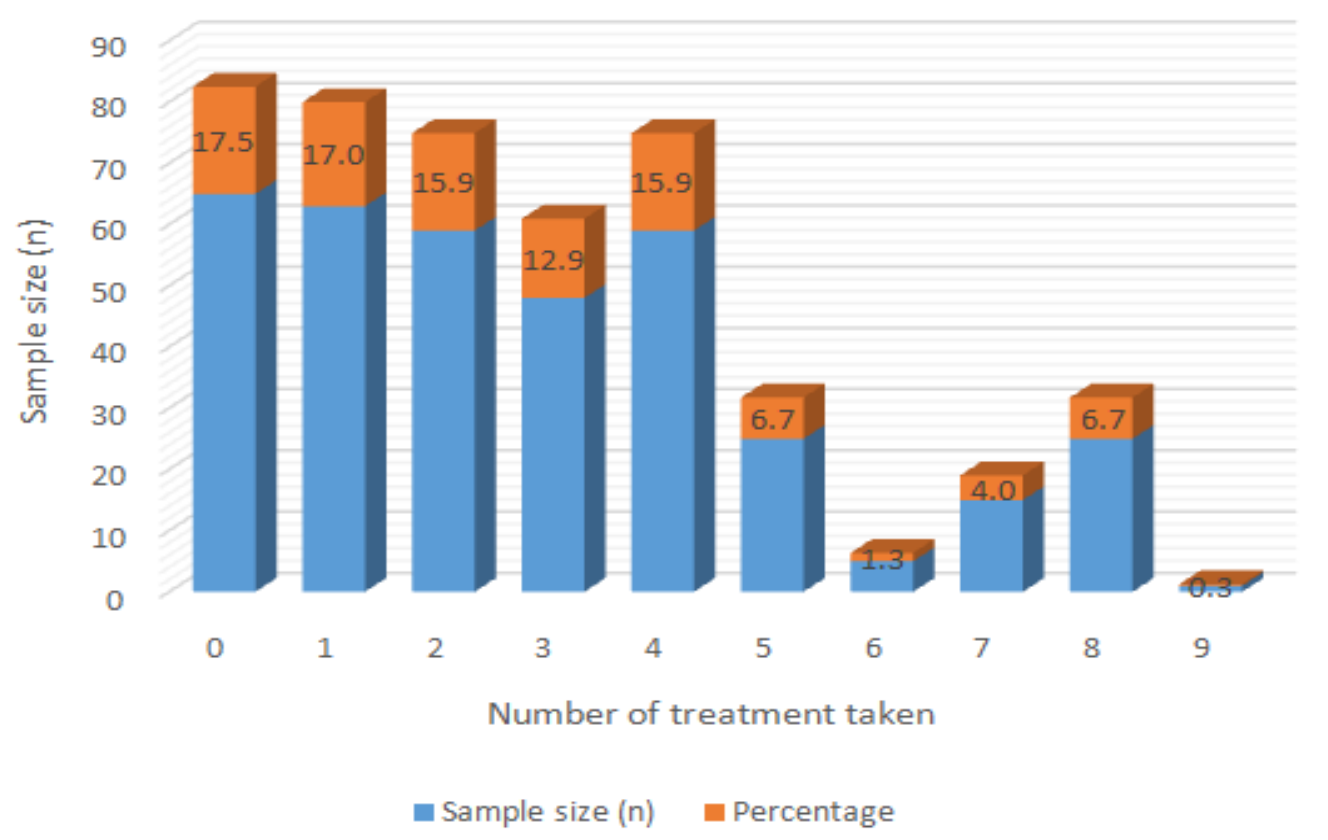

Figure 1: Distribution of annual ivermectin $\left(\right.$ Mectizan $\left.^{\circledR}\right)$ treatment compliance. Participants who did not take ivermectin are the non-compliant $(0)$ and those who took between 1-9 doses are the compliant.

At the time of this study, the villages that were expected to have taken ten annual treatments from 1994-2003 had mean of $6.2(62 \%)$ doses with a range of $1(10 \%)$ to $10(100 \%)$. One of the sentinel villages, Bomjock, had one treatment dose at the inception of Mectizan ${ }^{\circledR}$ distribution within the study area in 1994. Kurmin Gwaza and Angwar Maisaje had 4, Gidan Tama had 10 and others had 8. By implication, the individual compliance rates in the 6 sentinel villages were generally very low as shown on Table 1 . The average ranging between 7.0 to 78.7 treatment compliance and percentage doses taken were $82.4 \pm 6.3 \%$ and $34.3 \%$, respectively. Those with palpable nodules were $28(6.4 \%)$ and $16(3.7 \%)$ microfilaria prevalence in the sentinel sites $(n=438)$. Microfilaria was not seen in Sabon Gantan (n=100) and Gidan Tama (n=61),
1(1.56\%) case in Kurmin Gwaza ( $\mathrm{n}=64), 3(4.47 \%)$ in Gantan $(\mathrm{n}=68) ; 5(7.69 \%)$ in Ungwan Shaho $(n=65)$ and $7(9.0 \%)$ in Bomjock $(n=80)$. The highest skin microfilaria load was 18 per snip. The changes in parasitological data when compared with baseline data are shown in Table 2. There was a significant reduction $(\mathrm{p}<0.05)$ in skin microfilaria prevalence from 201(37.9\%) pretreatment baseline compared to $17(4.6 \%)$ at postdecade of MDA. Similarly, skin mf density, community microfilaria load and palpable nodule were significantly reduced $(\mathrm{p}<0.05)$ from $77(14.5 \%)$ to $28(6.4 \%)$. The palpable nodule rate and skin microfilaria prevalence did not show any strong correlation with both age and number of individual treatments ranging from 2-8 annual doses. 
Table 1: Village treatment compliance, palpable nodule and skin microfilaria prevalence rates at postdecade intervention

\begin{tabular}{|c|c|c|c|c|c|c|}
\hline \multirow{2}{*}{$\begin{array}{l}\text { Study village } \\
\text { A. Sentinel }\end{array}$} & \multirow{2}{*}{$\begin{array}{l}\text { Sample } \\
\text { size (n) }\end{array}$} & \multirow{2}{*}{$\begin{array}{c}\text { Dosage } \\
(1-10)\end{array}$} & \multicolumn{2}{|c|}{ Treatment compliance } & \multicolumn{2}{|c|}{ Prevalence rates $(\%)$} \\
\hline & & & $\begin{array}{c}\text { Population } \\
\text { coverage } \delta(\%)\end{array}$ & $\begin{array}{c}\text { Percentage } \\
\text { doses } \$\end{array}$ & Nodule & Skin mf \\
\hline Bomjock & 80 & 1 & $45(56.3)$ & 7.0 & $5(6.3)$ & $7(8.75)$ \\
\hline Gidan Tama & 61 & 10 & $57(93.4)$ & 78.7 & $9(14.8)$ & 0 \\
\hline Ungwar Shaho & 65 & 8 & $57(87.7)$ & 40.3 & $6(9.4)$ & $5(7.8)$ \\
\hline Kurmin Gwaza & 64 & 4 & $53(82.8)$ & 22.7 & $4(6.0)$ & $1(1.49)$ \\
\hline Gatan & 68 & 10 & $54(79.4)$ & 18.5 & $1(1.5)$ & $3(4.54)$ \\
\hline Sabon Gatan & 100 & 7 & $95(95.0)$ & 38.5 & $3(3.0)$ & 0 \\
\hline Total $($ Mean \pm Stdev $)$ & 438 & 6.7 & $361(82.4 \pm 6.3)$ & $34.3 \pm 21.4$ & $28(6.8 \pm 4.8)$ & $16(3.8 \pm 3.0)$ \\
\hline \multicolumn{7}{|l|}{ B. Control Villages } \\
\hline Rami Kura* & 42 & 2 & $12(28.6)$ & 3.6 & $6(14.3)$ & $1(2.38)$ \\
\hline Ungwar Maisaje* & 57 & 10 & $48(84.2)$ & 20.5 & $2(3.5)$ & 0 \\
\hline Ungwar Kongo* & 33 & 9 & $23(69.7)$ & 20.0 & $7(21.2)$ & 0 \\
\hline Ibika & 62 & 0 & $1(1.6)$ & 0 & $3(4.8)$ & 0 \\
\hline Sub-total & 194 & 5.3 & $84(43.3 \pm 32.8)$ & 11.0 \pm 9.3$)$ & $18(9.3 \pm 7.2)$ & $1(0.5)$ \\
\hline Total $($ Mean \pm Stdev $)$ & 632 & 6.1 & $445(67.8 \pm 30.8))$ & $25.0 \pm 23.1$ & $46(8.5 \pm 6.4)$ & $17(2.5 \pm 3.4)$ \\
\hline
\end{tabular}

The sign $\delta$ represent sample sizes that took 1-9 Mectizan ${ }^{\circledR}$ treatment doses. The percentage values of total actual doses divided by total expected doses of the sample population $(\S)$. *These control villages were enlisted for mass drug administration but had no baseline data. Standard deviation from mean (Stdev).

Table 2: Comparing baseline with post-decade treatment parasitological data

\begin{tabular}{lcccl}
\hline Parameter & $\begin{array}{l}\text { Baseline data } \\
(\mathbf{n = 5 3 1})\end{array}$ & $\begin{array}{l}\text { Post- } \\
\text { Treatment } \\
\text { data }(\mathbf{n = 4 3 8})\end{array}$ & $\begin{array}{l}\text { Significant } \\
\text { difference }\end{array}$ & Remarks \\
\hline $\begin{array}{l}\text { Skin mf prevalence } \\
\text { Skin mf density }\end{array}$ & $\begin{array}{c}201(37.9 \%) \\
17.7\end{array}$ & $\begin{array}{c}17(4.6 \%) \\
1.7\end{array}$ & $\begin{array}{l}\mathrm{p}<0.05) \\
\mathrm{p}<0.05\end{array}$ & $\begin{array}{l}\text { Reduced mf due to clearance. } \\
\text { Effect on female fecundity to } \\
\text { release mf. }\end{array}$ \\
$\begin{array}{l}\text { Highest skin mf } \\
\text { density }\end{array}$ & 145 & 18 & $\mathrm{p}<0.05$ & Skin snip mf count \\
CMFL & 1.7 & 0.06 & $\mathrm{p}<0.05$ & Geometric mean mf load \\
Palpable Nodule & $77(14.5 \%)$ & $28(6.4 \%)$ & $\mathrm{p}<0.05$ & Probable remission of nodules \\
\hline
\end{tabular}

$\mathrm{CMFL}=$ Community microfilaria load, $\mathrm{mf}=$ microfilaria

DOI: http://dx.doi.org/10.4314/ejhs.v27i2.5 
Moderate or not too serious form of itching was the main complaint among $14.8 \%(n=55)$, and few patients claimed that it was more intense after ivermectin treatment. Eight persons $(2.2 \%)$ had leopard skin, and few, 15(4.0\%), showed one or more forms of onchocercal skin changes as shown in Table 3. They include papular onchocercal dermatitis, chronic onchocercal dermatitis, 2; hernia, 3; a case of elephantiasis of the scrotum at the earlier stage of development. Thirty persons $(8.0 \%)$ had visual impairment based on VA of $6 / 18$ and above, with 2 partial and 7 total blind cases $(2.4 \%)$ which included one new blind case. Moderate or not too serious form of itching was the main complaint among $23.53 \%(n=60)$ of the four control villages. Five persons $(1.96 \%)$ had leopard skin, and few, 10(4.0\%), showed one or more forms of onchocercal related skin changes. Twenty-five persons (9.8\%) had visual impairment based on VA of $6 / 18$ and above. Most cases of blindness were due to accident, old age and childhood disease. Those with palpable nodules were $24(9.41 \%)$, and the microfilariae prevalence of the control sample population was
$1(0.4 \%)$ with 18 and 7 microfilariae per right and left iliac skin snip respectively.

Among the post-decade onchocercal related skin manifestations such as onchodermatitis, leopard skin and the ocular clinical symptoms of poor visual impairment and blindness were significantly higher $(p<0.05)$ in sentinel villages compared with control villages. Unlike the sentinel villages, all cases of blindness in the control villages were not due to onchocercal related causes. Evidence of itching of $14.8 \%$ $(n=55)$ and palpable nodule rate $28(6.4 \%)$ in sentinel villages were lower compared with $23.53 \%(n=60)$ and $9.41 \%(n=24)$ recorded in control villages. Observed differences were not statistically significant $(p>0.05)$. However, the skin $\mathrm{mf}$ prevalence was significantly higher $(p<0.05)$ in the sentinel villages than in the control villages with 17 (4.6\%) versus 1 (0.4\%), respectively. The only microfilaria positive case was in a 35-year-old male who had taken ivermectin twice. A case of an individual with nine palpable nodule without any skin microfilaria took Mectizan four months before the study.

Table 3: Comparing baseline with post-treatment clinical data

\begin{tabular}{|c|c|c|c|c|}
\hline $\begin{array}{l}\text { Clinical signs and } \\
\text { symptoms }\end{array}$ & $\begin{array}{l}\text { Baseline data } \\
(n=531)\end{array}$ & $\begin{array}{l}\text { Post-Treatment } \\
\text { data }(n=438) \text {. }\end{array}$ & Difference & Remarks \\
\hline Dermal changes & $51(9.6)$ & $15(4.0)$ & $\begin{array}{l}\text { Significant } \\
(p<0.05)\end{array}$ & $\begin{array}{l}\text { Decrease in overall } \\
\text { skin clinical signs }\end{array}$ \\
\hline Itching & $382(72)$ & $55(14.8)$ & $\begin{array}{l}\text { Significant } \\
(\mathrm{p}<0.05)\end{array}$ & $\begin{array}{l}\text { Reduction in severity } \\
\text { of itching }\end{array}$ \\
\hline $\begin{array}{l}\text { Papular } \\
\text { Onchodermatitis }\end{array}$ & $38(7.2)$ & $2(0.5)$ & $\begin{array}{l}\text { Significant } \\
(p<0.05)\end{array}$ & $\begin{array}{l}\text { Remission of } \\
\text { reactive skin rashes }\end{array}$ \\
\hline $\begin{array}{l}\text { Chronic } \\
\text { Onchodermatitis }\end{array}$ & $26(4.9)$ & $2(0.5)$ & $\begin{array}{l}\text { Significant } \\
(\mathrm{p}<0.05)\end{array}$ & $\begin{array}{l}\text { Remission of chronic } \\
\text { rashes }\end{array}$ \\
\hline Leopard Skin & $10(1.9)$ & $14(3.8)$ & Significant & $\begin{array}{l}\text { Increase in leopard } \\
\text { skin }\end{array}$ \\
\hline $\begin{array}{l}\text { Visual Impairment } \\
\text { VA of } 6 / 18 \& \text { above }\end{array}$ & $20(3.8)$ & $30(8.0)$ & $\begin{array}{l}\text { Not } \\
\text { significant } \\
(p>0.05)\end{array}$ & $\begin{array}{l}\text { Increased poor } \\
\text { vision and eye } \\
\text { lesions }\end{array}$ \\
\hline Blindness & $6(1.1)$ & $7(2.4)$ & $\begin{array}{l}\text { Not } \\
\text { significant } \\
(p>0.05)\end{array}$ & $\begin{array}{l}\text { Halted the } \\
\text { development of new } \\
\text { blind cases }\end{array}$ \\
\hline
\end{tabular}

The probability values $(\mathrm{p}<0.05)$ show statistical significance by unequalled data t-test. Figures in parenthesis are percentages.

DOI: http://dx.doi.org/10.4314/ejhs.v27i2.5 


\section{DISCUSSION}

Assessment of the long term impact of annual ivermectin treatment of endemic communities is needed to determine the feasibility of controlling and eventually eradicating onchocerciasis. The impact of ComDTI on public health in onchocerciasis endemic communities has been reported to be impressive $(20,21,22)$. It was observed that the skin clinical symptoms including palpable nodules dropped over the base line figures. Many expressed having been relieved from severe skin itching which was widespread before the Mectizan distribution started in these areas. The few who experienced itching reaction did not report any serious limitations to warrant discontinuing with treatment.

These results were in total contrast to baseline figures which ranges between $25-72 \%$ for the villages (7). In addition to this impressive performance by the drug, it seems that the fear that non-compliance may adversely affect the control method may not be a serious problem as hitherto assumed. The absence of infection and clinical manifestations among the younger age group below 30 years was a confirmation of a possible break in disease transmission cycle. An early study undertaken by Boussinesq et al. (23) showed that the pretreatment community microfilarial loads (CMFL) decreased from 5.5 and 25.1 microfilariae per snip after 32 months to only 24 and $51 \%$ of the initial values, respectively. In a third village treated once had the mean microfilaria density 28 months after treatment to be only $12 \%$ of the initial value.

From our finding, the incidence of visual impairment showed remarkable increase over those of baseline data. This could be attributed to the fact that those hitherto seen to have one form of eye lesion now manifest as poor visual acuity. Just like the only new case of blindness recorded was in a man who was said to be blind 2 years after the treatment started. This is not unexpected as non-reversible lesion will not be affected by treatment $(24,25)$. The patient already had optic nerve disease before treatment started. Another notable observation was the claim of disappearance of nodules and remarkable improvement in severity of itching. A typical case was that of a man who claimed that the severity of the leopard skin had improved along with reduced severe itching. Similar findings have been documented in other studies by Ogbuagu et al. and Emuka et al. (26,27). This is contrary to report (28) that after three doses, $44 \%$ of the patients remained skin snip positive. A long term effect of the treatment was not assessed.

It is plausible for the continued presence of palpable nodules and skin microfilaria despite varied annual ivermectin treatment doses to be attributed to sub-optimal responses. Elsewhere, inability to clear $\mathrm{mf}$ from skin after multiple treatments has been documented (29). It is worth mentioning that the low prevalence and skin $\mathrm{mf}$ density especially among inhabitants of Bomjock which had only received one treatment proved the long term efficacy of single dose ivermectin. Whether this could be attributed to reduce turnover of microfilaria production and release, or increased and sustained microfilaria elimination on the part of the host as suggested by Schulz-key and Karam (30) remained subjective. Another possibility is to suspect the role of partial drugfacilitated cell mediated immunity may play in preventing microfilariae from repopulating the skin on a long-term basis. Should that be the case, it will be an added advantage previously not anticipated when ivermectin treatment of onchocerciasis was approved for field use.

Earlier reports have documented delay in repopulation between 9-12 months (31). Due to lack of suitable model host for laboratory study, the high cost and ethical consideration for subjecting humans to placebo trial for up to ten years have precluded determination of the outcome of a single treatment. It has been documented by Pacque et al. (32) that up to 33\% of patients in non-endemic areas were cured with only 1 dose of ivermectin. Thus, the study of treatment compliance rate after a decade of intervention and the observed impact of single dose treatment on skin $\mathrm{mf}$ load and nodule rates clearly support the efficacy of single-dose treatment.

It was feared that non-compliance to regular annual treatment will seriously jeopardize the attainment of the set target or objective $(33,34)$. An astonishing finding that despite receiving only 
one and few treatment doses, onchocerciasis prevalence was drastically reduced from $72 \%$ to 9\% in Bomjock and overall. The same applies to the infection intensity. The precarious public health situation of river blindness in these villages within the Gurara river basin was being mitigated. Moreover, black fly uptake of mf has been shown not to be associated with the level of skin $\mathrm{mf}$ density (8). Therefore, the surrounding villages need to be enlisted for treatment to avert few pockets of few infected individuals serving as reservoir of infection.Yet, a panacea for effective control based on ComDTI is to attain $100 \%$ geographic coverage and at least 50\% individual treatment compliance. The mechanism of sustained elimination of parasite reservoir may be accomplished if compliance rate is improved (35). It will require advocacy visits to mobilize the people to comply with annual treatment.

The outcome of this study has confirmed that repopulation of skin with $\mathrm{mf}$ may just be a transient features observed immediately after treatment. The long term impact of treatment could have resulted in clearing skin $\mathrm{mf}$ and remission of nodules as observed in this study. It has been reported by Pion et al. and Basáñez et al. $(36,37)$ that $O$. volvulus microfilaria density measured after a first treatment with ivermectin, and thus probably the rate of skin repopulation by microfilariae $(\mathrm{mf})$ varies according to several host factors. A mathematical model (38) had predicted reduction in microfilaridermia by $98-99 \%$ after 1-2 months treatment, which corresponds to the time when the fraction of females harbouring live microfilariae were at the lowest (reduced by around $70 \%$ from its original value).

The isolated $\mathrm{mf}$ positive case that was recorded in Rami Kura in a 35-year-old man who had taken 2 doses of Mectizan calls for concern. Whether this was a case of non-responder as observed (29) or resistance to ivermectin as suggested by Osei-Atweneboana et al. (39) remained unknown. This study has confirmed that the adjoining villages do not pose any threat of serving as reservoir of infection for re-invasion of endemic areas after post control. Interestingly, the case of the young boy with 9 nodules but without skin $\mathrm{mf}$ is a typical example. He took treatment that year before the screening exercise.
Inference drawn from this study holds a contrary opinion to the predicted duration required to attain elimination of $\mathrm{mf}$, as suggested via mathematical model EPIONCHO, which proposed that it will only be achievable within 25 years for the setting with $51 \%$ baseline mf prevalence (40). Annual ivermectin mass treatment strategy may not require longer continuation to achieve the pOTTIS as averse in some quarters.

\section{ACKNOWLEDGMENTS}

The author thank the Management of NITR for funding this project and permission to publish the research findings. The technical assistance rendered by Mr. J. Gazama and Mr. Samson Itua is worthy of note. The logistic support given by the Chairman, Director of Health, and the Onchocerciasis Coordinator of Kachia Local Government Area of Kaduna State, is duly acknowledged. The author highly appreciates the cooperation of the village heads and people of the communities who volunteered to participate without which it would not have been possible to undertake the study.

\section{REFERENCES}

1. Burnham G, Mebrahtu T. The delivery of ivermectin (Mectizan). Trop Med Int Hlth. 2004; 9:A26-A44.

2. Aziz MA, Diallo S, Diop IM, Larviere M, Porta M. Efficacy and tolerance of ivermectin in human onchocerciasis. Lancet, ii. 1982; 8291: 171-173.

3. WHO (World Health Organization). WHO country cooperation strategy: Federal Republic of Nigeria,2007; 2002-2007.

4. Collins RC, Gonzales-peralta C, Castro J.Zea_Flores G, Cupp MS, Richards FO Jr, Cupp EW. Ivermectin: reduction in prevalence and infection intensity of Onchocerca volvulus following bi-annual treatment in five Guatemala communities. Am J Trop Med Hyg. 1992; 47 (2): 156-169. doi:10.1111/j.1365-3156.2008.02126.x

5. Coffeng LE, Stolk WA, Hoerauf A, Habbema D, Bakker R, Hopkins AD,de Vlas SJ. Elimination of African onchocerciasis: modelling the impact of increasing the frequency of ivermectin mass treatment. PLoS One. 2014; 9(12):e115886 
6. Abiose, A. Operational research for ivermectin based onchocerciasis control in Nigeria. Nig $J$ Ophthal. 1992; 2(1): 32-37.

7. Osue, H. O. Onchocerca volvulus AntigenSpecific IgA, IgM, IgG Class and SubClass Antibodies and circulating eosinophils in clinical onchocerciasis patients from Kachia LGA of Kaduna State. M. Sc. Thesis, Ahmadu Bello University, Zaria. 1996;

8. Soumbey-Alley E, Basanez MG, Bissan Y, Boatin BA, Remme JH, Nagelkerke NJ, de Vlas SJ, Borsboom GJ, Habbema JD. Uptake of Onchocerca volvulus Nematoda: Onchocercidae) by Simulium (Diptera: Simuliidae) is not strongly dependent on the density of skin microfilariae in the human host. $J$ Med Ento. 2004; 41(1):83-94.

9. Poolman EM, Galvani AP. Modelling Targeted Ivermectin Treatment for Controlling River Blindness. American J Trop Med Hyg. 2006; 75(5):921-927.

10. Plaisier AP, van Oortmarssen GJ, Habbema JDF, Remme J, Alley ES. ONCHOSIM: a model and computer simulation program for the transmission and control of onchocerciasis. Comp Meth Prog Biomed. 1990; 31(1):43-56.

11. Turner HC, Walker M, Churcher TS, Basáñez MG. Momdelling the impact of ivermectin on River Blindness and its burden of morbidity and mortality in African Savannah: EpiOncho projections. Parasi Vect. 2014; 7:241- 249.

12. Stolk WA, Walker M, Coffeng LE, Basáñez M,de Vlas SJ. Required duration of mass ivermectin treatment for onchocerciasis elimination in Africa: a comparative modelling analysis. Parasit Vect. 2015; 8:552-doi: 10.1186/s13071-015-1159-9

13. Remme JH, Blas E, Chitsulo L, Desjeux PM, Engers HD, Kanyok TP, Kengeya Kayondo JF, Kioy DW, Kumaraswami V, Lazdins JK, Nunn PP, Oduola A, Ridley RG, Toure YT, Zicker F, Morel CM. Strategic emphases for tropical diseases research: a TDR perspective. Trends Parasitol. 2002; 18:421-426.

14. WHO (World Health Organization). Success in Africa: the Onchocerciasis Control Programme in West Africa, 1974-2002. WHO Geneva, Switzerland. Techn Rep Ser.2005; No. 885.

15. Katabarwa M, Eyamba A, Habomugisha P, Lakwo T, Ekobo S, Kamgno J, Kuete T, Ndyomugyenyi R, Onapa A, Salifou M, Ntep M,
Richards FO. After a decade of annual dose of mass ivermectin treatment in Cameroon and Uganda, onchocerciasis transmission continues. Trop Med Intern Hlth. 2008; 13(9): 1-8. doi:10.1111/j.1365-3156.2008.02126.

16. Diawara L, Traore MO, Badji A, Bissan Y, Doumbia K, Goita SF, Konate L, Mounkoro K, Sarr MD, Seck AF, Toe L, Touree S, Remme $\mathrm{JH}$. Feasibility of onchocerciasis elimination with ivermectin treatment in endemic foci in Africa: first evidence from studies in Mali and Senegal. PLoS Negl Trop Dis. 2009; 3: e497.

17. Traore MO, Sarr MD, Badji A, Bissan Y,Diawara L, Doumbia K, Goita SF, Konate L, Mounkoro K, Seck AF, Toe L, Toure S, Remme JH. Proof-of-principle of onchocerciasis elimination with ivermectin treatment in endemic foci in Africa: final results of a study in Mali and Senegal. PLoS Negl Trop Dis. 2012;6: e1825.

18. Tekle AH, Elhassan E, Isiyaku S, Amazigo UV, Bush S, Noma M, Cousens S, Abiose A, Remme $\mathrm{JH}$. Impact of long-term treatment of onchocerciasis with ivermectin in Kaduna State. Nigeria: first evidence of the potential for elimination in the operational area of the African Programme for Onchocerciasis Control. Parasit Vect. 2012; 5:28.

19. Murdoch ME, Hay RJ, MacKenzie CD, Williams JF, Ghalib HW, Cousens S, Abiose A, JonesBR. A clinical classification and grading system of the cuteneous changes in onchocerciasis. Br J Derm. 1993; 1299(3): 260269.

20. Benton B. Economic aspects of onchocerciasis control through the African Programme for Onchocerciasis Control: An overview. Ann Trop Med Parasit. 1998; 92(Suppl 1): S33-S39.

21. Dadzie Y, Neira M, Hopkins D. Final report of the conference on the eradicabilityof onchocerciasis. Filaria.2003; J 2: 2.

22. Boatin BA, Richards FO Jr. Control of onchocerciasis. Advances in Parasitology. 1993; 61: 349-394.

23. Boussinesq M, Prod'hon J, Chippaux JP, Quillévéré D. Long-term effect of a single dose of ivermectin on skin microfilarial density in an endemic onchocerciasis area of North Cameroon. Ann Soc Belge Méd Trop. 2006; 73: 189-196 (in French).

DOI: http://dx.doi.org/10.4314/ejhs.v27i2.5 
24. Awadzi K, Bird AC, Schulz-key H. Ophthalmological results from a placebo controlled comparative 3-dose ivermectin study in the treatment of onchocerciasis. Trop Med Parasi. 1989; 40: 335-360.

25. Abiose A, Jones BR, Cousens SN, Murdoch I, Cassels-Brown A, Babalola OE, Alexander NDE, Nuhu I, Evans J, Ibrahim UF, Mahmood AO. Reduction in the incidence of optic nerve disease with annual ivermectin control. Lancet.1993; 341: 130-134.

26. Ogbuagu K F, Eneanya CI. A multi-centre study of the effect of Mectizan treatment on onchocercal skin disease: clinical findings. Ann Trop Med Parasi. 1998; 92 (Suppl. 1): S139-45.

27. Emuka EC, Osuha E, Miri ES, Oyenama J, Amazogo U, Obijuru C, Osuji K, Ekeayanwu J, Amadiegwu S, Korve K, Richards FO. A Longitudinal study of impact of repeated mass ivermectin treatment on clinical manifestations of onchocerciasis in Imo State, Nigeria. Am J Trop Med Hyg. 2004; 70(5):556-561.

28. Njoo FL, Stilma JS, Van Der Lelij A. Effects of repeated ivermectin treatment in onchocerciasis. Doc. $\quad$ Ophthalmol. 1992; 79: 261. doi:10.1007/BF00158256

29. Awadzi K, Boakye DA, Edwards G,Opoku NO, Attah SK, Osei-Atweneboana MY et al. An investigation of persistent microfilaridermias despite multiple treatments with ivermectin, in two onchocerciasis-endemic foci in Ghana. Ann Trop Med Parasit. 2004; 98(3):231-249.doi: 10.1179/000349804225003253

30. Schulz-key H, Karam M. Periodic reproduction of Onchocerca volvulus. Parasit Today. 1986; 2(10):284-286.

31. Boatins BA, Ougard J-M, Alley ES, Dembélé N, Weiss N, Dadzie KY. The impact of Mectizan on the transmission of onchocerciasis. Ann Trop Med Parasit. 1998; 92(Suppl 1): S47-S60.

32. Pacque M, Elmets C, Dukuly ZD, et al. Improvement in severe onchocercal skin disease after a single dose of ivermectin. Am J Med. 1991; 90(5): 590-594.
33. WHO (World Health Organization). Onchocerciasis and its control. Report of a WHO Expert Committee on Onchocerciasis Control. WHO Tech Rep Ser.1995; 852:1-104.

34. Okeibunor JC, Ogungbemi MK, Sama M, Gbeleou SC, Oyene U, Remme JH. Additional health and development activities for community-directed distributors of ivermectin: threat or opportunity for onchocerciasis control? Trop Med Internl Hlth.2004; 9(8): 887-896.

35. Remme JH, Amazigo U, Engels D, Barryson A, Yameogo L. Efficacy of ivermectin against Onchocerca volvulus in Ghana. Lancet. 2004; 370:1123-1124; author reply 1124-1125.

36. Pion SD, Grout L, Kamgno J, Nana-Djeunga H, Boussinesq M. Individual host factors associated with Onchocerca volvulus microfilarial densities 15, 80 and 180 days after a first dose of ivermectin. Acta Tropica. 2011; 120 (Suppl 1):S91-9. doi: 10.1016/j.actatropica.2010.05.004.

37. Basáñez M-G, Pion SDS, BoakesE, Filipe JAN,Churcher TS, Boussinesq M. Effect of single-dose ivermectin on Onchocerca volvulus: a systematic review and meta-analysis. The Lancet Infect Dis. 2008; 8(5), 310-322. DOI:http://dx.doi.org/10.1016/ S1473-3099 (08)70099-9

38. Basáñez M-G, Ricárdez-Esquinca J. Models for the population biology and control of human onchocerciasis. Trends Parasit. 2001; 17: 430438

39. Osei-Atweneboana MY, Awadzi K, Attah SK, Boakye DA, Gyapong PO, Prichard RK. Phenotypic Evidence of Emerging Ivermectin Resistance in Onchocerca volvulus. PLoS Negl Trop Dis. (2011); 5(3):e998.

40. Thylefors B, Alleman M. Towards the elimination of onchocerciasis. Ann Trop Med Parasit. 2006; 100: 733-746. 